\title{
The Natural and Human Environments in Nigeria: Their Implications for Architecture
}

\author{
IMAAH, NAPOLEON. ONO
}

\author{
Department of Architecture, Rivers State University of Science and Technology, \\ P. M. B. 5080, Port Harcourt, NIGERIA. Telephone: +234-(0)8033126194.E-mail: noimaah@yahoo.co.uk
}

\begin{abstract}
The paper asserts that a desirable architecture and the environment intertwine inseparably in complex relationships, which, usually, make the coexistence of these dynamic intricate and diverse factors difficult. The paper separates these factors into natural and artificial components and relates them to the sociocultural environments prevalent in Nigeria. This paper elaborates on the various features, which designers often ignore, and recommends a simultaneous interaction between architecture and the environment. Hence, the paper established a "comfort zone," which simultaneously combines the effects of temperature, rainfall, wind velocity, and relative humidity in a single design process. This paper, also, examines some socio-cultural aspects of Nigerian natural geographic environments in relationship to climatic factors; and hence their implications in the determination of design decisions. The paper, subsequently, suggests solutions, which we hope, would provide a harmonious blend between natural and human environments through architecture. In conclusion, the paper provides useful guidelines to architects, particularly foreigners to Nigeria building environments, who would wish to design befitting environmental friendly buildings for Nigerian. @ JASEM
\end{abstract}

Nigeria is a multiethnic nation, with over 250 cultural groups and languages, multiple religious groups, and varied environmental conditions; making Nigeria a complex linguistic, social, and cultural mosaic ${ }^{(1)}$. Like every other such environment, Nigeria has its own peculiarities with many contending contradictory variables that affect its peoples and their diverse life styles. The paper opines that the interactions of these factors determine the appropriate building type and technology most suitable for the way of life pertinent to the peoples who live in it. The paper examines some of these factors and their combined interactive effect on the built environment in terms of either unity in diversity or unity of opposites. Evidence shows that diversity has disrupted the unity of architecture in various ways resulting in a clash of cultures, religious riots and dissonance designs in a decomposing environment. The author is of the considered opinion that the environment itself provides an incontrovertible multiform expressions that nature justly adjusts to fit flawlessly into this heterogeneous natural environment. The paper demonstrates that these examples from nature, in the light of historical and scientific facts, can be applicable to the solution of building problems in harmony with the Nigerian multifarious, multiethnic and multicultural environment. The absence of dependable documented records, of defined norms for building designs, has made indiscriminate inroad of many foreign ideologies, philosophies and styles into architecture easy, through the indiscriminate admission of many a cacophony of eclectic architecture.

Environmental Concerns: Plants and Animals Population pressure in Nigeria has accelerated serious environmental deterioration; while a history of unstable and ineffective governments have hampered efforts to control and conserve natural resources. As a result of environmental degradation, Nigeria has lost about 84 per cent of its total forest cover and around 90 per cent of its moist forests, the remainder of which exist in small reserves. By 1995, woodland accounted for only about 29 per cent of the country's total land area ${ }^{(2)}$ of $923,768 \mathrm{~km}^{2} \quad\left(356,669 \mathrm{mi}^{2}\right) \quad$ (Wikipedia Encyclopedia, 2008). The root causes of the environmental deterioration in Nigeria are many. Some of the causes emanate from the fact that: Nigeria has a poorly organized national system for the preservation of nature reserves, game reserves, and national parks in addition to a forest management system. Additionally, a law enforcement system to protect a system of infrastructure is either lacking or inefficient, thereby encouraging frequent abuses of protected lands. Furthermore, the considerable wetlands of Nigeria which include vast mangrove swamps along the coast, riverine wetlands and expansive floodplains pose problems to infrastructural development. The protection of these wetlands is also limited except in the areas around Lake Chad. Desertification, made worse by massive water impoundment and irrigation schemes, is another major problem yet unresolved. Uncontrolled grazing and livestock migration put further pile pressure on the devastated environment in the same areas devastated by desertification. Other environmental threats the Nigerian environment include poaching and settlement within protected areas, brushfires, increasing demand for fuelwood and timber, road expansion, and oil extraction activities. The visible result of these pressures on account of these activities is a desolate denuded environment. Bereft of its natural alluring aesthetics, exposed to desertification, and erosion 
these naked areas await the worst woes of the war consequent upon worldwide warming.

Meanwhile, the Nigeria government is not tackling the burning issues. For example although signatory to the World Heritage Convention, Nigeria has no recognizable sites yet; but only one biosphere reserve: "Man and the Biosphere Program," designated under the United Nations Educational, Scientific, and Cultural Organization (UNESCO). For another instance of inefficiency, Nigeria has ratified international agreements concerning: biodiversity, climate change, endangered species, hazardous wastes, law of the sea, marine dumping, marine life conservation, nuclear test ban, ozone layer, and whaling (3) without implementing the contexts of these conventions into the content of the Nigeria environment.

\section{Nature and its Nurturing Role in Architecture}

The paper affirms that nature serves as an inexhaustible reservoir of resources. According to Emerson, nature is an endless combination and repetition of very few laws; she hums the wellknown air through innumerable variations. For instance, endless examples abound in the colour combinations, structural stability, stimulating significant symbols, imagery, and the melodies of natural sound of music emanating from the animate world. Therefore, we could simulate fantastic forms from nature, which, subsequently, stimulate our creative capabilities (4). Thus, nature inspires artistes, poets and architects in sculpture, fine art, applied arts, plastic arts, visual arts, with symbols and metaphors. Thus, "It might be said that in any era of history, in any culture, in every style of writing, writers have referred to nature and made of it a symbol for something else - either the good life, or the forces that control nature or a place from the evils of urbanization, or any number of other things. In a similar vein, Emerson, the American transcendentalist in his essay "Nature," confirms that people draw most metaphors in language from nature. $^{(5)}$

The paper opines that architects and architecture can also benefit from examples that abound in nature. The synthesis of examples from nature has spreads wide into the fields of medicine, engineering and poetry. Thus, we can synthesize examples of colours, structural suitability, and fractal forms from nature into architecture. These natural examples in Nigeria include: stimulating spectacular spectrum of colours, the endless flourish of flora and fauna along with the colourful dazzle of the animate and the inanimate world. Natural colours occur in the plumages of bright birds, countless colors of tree leaves, and the endless earth colors, the watercolors of the oceans, seas, rivers and lakes, as well as the natural and artificial colour combining capability of the ingenious human mind. The synthesis of nature into architectural composition and construction comes in various marvelous ways, which are now influencing bionics, bio-mimetic, tectonics and construction technologies globally. ${ }^{(6)}$ The interrelationships of nature and architecture may fall into three broad groups, namely: Construction techniques and tectonics, which enable people to synthesise the structural arrangement of living organisms and plants into architecture.; Climatology, which studies the reactions of plants and living organisms to climatic conditions such as sunshine, temperature, moisture, relative humidity and wind, enables us to transfer the results to suit man through an acclimatized architecture.; Aesthetics, as the art and science of the beautiful or the ugly, which simulates what stimulates and rejects the repulsive from the nebulous natural examples of adaptable beauty and repulsive ugliness, enables us to design naturally beautiful architecture.

A glance at the Nigerian environment gives us ample samples of examples, which we can simulate from nature. Consequently, these stimulating natural examples can inspire us into creating authentic environmental friendly architecture to the specific environments found in Nigerian. For example: The structural stability of seashells, the engineering economics of the eggshell and natural floral shapes can translate into sources of inspiration in designing geodetic domes and shell constructions.; The dynamic but stable structural system of the tree-stem, simulating roots as foundation, branches as structural members, and leaves as the shelter-providing roof; or the rocksteady stability of the immobile mountains, form the creative core component for the design of slabs; columns; beams and foundation design.; The architecture, technology and temerity of the termites show in the composition of the termitarium. Architecture, similarly, surfaces succinctly in the superb strength of the spider's steely snares or the fine, feeble but firm fibrous nests that are instructive sources of inspiration, which the Egyptians, Greeks, Romans, and particularly in modern architecture by Pier Luigi synthesized successfully into architectural designs and constructions (7) The confounding changeability of the colorful camouflaging chameleon serves as a source of inspiration in our search for adaptable safe solutions to survival in harmony with the ever-changing socio-cultural and environmental conditions.

\section{A SYNOPSIS OF NIGERIAN CLIMATIC ZONES}

\section{The Landscape}

Having examined the stimulating examples which we can simulate from nature, the paper discusses the specificities of the Nigerian landscape vis-à-vis their architectural implications. Specifically, 
Nigeria consists of four distinct geographical regions influenced by varying regimes of temperature, relative humidity, wind velocity and rainfall (Table.1). Along the coast is a belt of mangrove forests and swamps, stretching some 16 $\mathrm{km}$ inland in most places. Numerous lagoons and creeks cut this region. In the Niger delta region, the coastal belt extends some $100 \mathrm{~km}$ inland. Beyond the coast, lowlands follow a low plateau cut by rivers, especially the Niger and Benue. The River Niger and its tributaries - principally the Benue, Kaduna, and Sokoto rivers drain most of Nigeria. In the northeast, the rivers drain into Lake Chad. Rapids and seasonal fluctuations in depth restrict navigation of the Niger and its tributaries. Otherwise, the land gives way to a broad, hilly, forested belt that gradually rises to the rocky terrain of the Jos and Bauchi plateaux. Beyond these plateaux is a region of savannah, which stretches to the semi-desert Sahelian zone in the extreme north. A great plain, marked by occasional outcroppings of granite, the savannah region is Nigeria's main agricultural area. In the east is the Adamawa Plateau, which borders Cameroon, and contains Nigeria's highest point, the $2,042 \mathrm{~m}$ or $6,699 \mathrm{ft}$ Dimlang or Vogel Peak. (8) These peculiar geomorphologic factors, in my considered opinion, should determine the appropriate approach to the architectural, structural and aesthetic design in the Nigerian environment. From the analysis of the Nigerian environment, we can deduce that two distinct broad groups namely: the Rain Forest to the southern and the Dry Savannah to the northern parts of Nigeria respectively. These are further tonally divided by modifying factors such as altitude, power of prevailing winds, culture and population density, into many minor groups. It is the opinion that a harmonious combination of these various groups aught to form the basis of any decisions concerning the rationality or otherwise of building typology. The paper examines these groups and subsequently their simultaneous interrelationships in effective building conceptualization and decision-making.

\section{Vegetation Zones in Nigeria}

Vegetation zones in Nigeria are equivalent to the climatic zones. The well-watered zone in the south partly covers the remnants of the dense tropical forests that contain hardwoods such as mahogany and obeche. Oil palms are particularly plentiful. In the plateau and savannah regions, forests give way to grasslands and to such hardy trees as the baobab and the tamarind. In the extreme northeastern Sahel region, semi-desert vegetation prevails. There is also a marked difference between the animal kingdoms in these various ecological zones and their adaptation strategies. However, the large African mammals once indigenous to Nigeria have disappeared in the face of intense reckless settlement that has rattled the natural ecological balance. The original Nigerian who lived freely amidst nature is now caged and frozen in foreign air conditioners. The tragic disappearance of wild life, because of the damage to their natural habitat in a changed ecology, proves fatally instructive that without adjustment to the deteriorating environment, inhabitants, like the beast, might face serious negative environmental impact problems if they do not readapt their habits and habitats in harmony with the natural environment.

The vegetation of any place points at the ways nature has resolved the environmental imperative problems of suitability of form and function, through prudent solutions to style and structure. Nature reveals the degree of appropriate comfort and the limits of the type of construction that is possible within a given environment. Nigeria has two broad vegetation types the northern savannah and the southern rain forest. Obviously, this varied vegetation defines the folk architecture within these zones: The straw structures from the straw fields of the savannah and the thatch from the palms of the swamps of the rain forest. The strong winds prompts the round shapes of the perimeter walls of buildings that ward off violent wind velocities. The use of light dismountable and transportable tents is suitable for mobility inherent in the transient transhumance and nomadic culture of the savannah peoples. The flood resulting from the torrential rains of the terrain leads to the conceptualization of the canopy-like pitched roofs over the rectangular buildings, the stilt foundation mimicking the mangrove stilt-like root system, and the raftfoundation flowing from the ideas of houseboats that stand afloat above the floods in the southern rain forest of Nigeria. The natural wisdom displayed by the natives of the environment derives from the forms of nature that form the basis of folk and vernacular architecture. The paper notes that the building materials, which the heavy rains stimulate, are also derivable from the environment to produce locally affordable organic architecture (Table. 2).

Regrettably, the Nigerian building industry has not taken adequate steps to study her abundant natural examples. For instance, observations reveal that the traditional ways which were at peace with the environment have changed because of indiscriminate influx of conflicting foreign cultures, religions, technologies and architectural styles. This cumulative confusion causes the emergence of disagreeable forms with unnatural flawed functionalities. The introduction of the flat roof in the rainy southern and the pitched roof to the dry hot northern part of Nigeria, respectively, are good examples of reckless disrespect to the environment. The once available free natural materials: timber, thatch straw and water are becoming extinct in inverse proportion to the rise of the population and industrial exploitation, thereby making the masses in the rural areas unable 
to build even cheap thatch houses. The nouveau rich now build massive oppressive structures that are offensive to the sensibilities of restive impoverished villagers, while traditional building materials and construction techniques are waning and wasting. The paper identifies some of the ignorance in ignoring the natural examples. For instance, we notice, from a dendrological analysis, we deduce that the trees in the rain forest differ from those in the Savannah because of the combination of climatic factors and functions such as water, wind velocity, and geo-morphological factors. These trees show nature's way of handling issues, which also can be adapted to buildings. For instance, the tree leaves in the south are broad; arranged spirally and showing a broad surface area for effective transpiration and acquisition of air and light for photosynthesis. The leaves are also many to enable efficient transpiration in spite of high relative humidity situation. The trees shear their leaves when relative humidity reduces and eases the task of the leave in transpiration. On the other hand, the trees in the dry north have compact narrow needle-like leaves to enable them to conserve and reduce water during transpiration. In both environments, trees on weak soils tend to develop deep root systems for firmer grip on the soil and offer adequate resistance to wind pressure. These natural examples inspire us to determine important concepts in architectural designs; but they have not because we ignore them. For example, the type of leaves suggest the type of windows, revealing nature's ingenuity in dealing with high relative humidity or its scarcity indicating that the more the relative humidity the more the number of windows and the greater surface areas of the external walls needed to deal with it effectively. Similarly, The less the relative humidity is, the less the number of windows and the more compact the external surface areas of the external walls aught to be. The root system of the trees, which is a product of the environment, enables us to envisage and determine the suitable foundation and structure suitable for a particular soil type. The canopy of the tree leaves, suggest the shading role of the eaves of roofs and landscaping as a shading devices. The hard barks of the trees resemble thick skins or membranes, which architects copied into the once useful thick "breathing" brick walls in the commendable era of colonial architecture, either to repel repulsive external factors such as heat, or retain internal clement conditions such as entrapped cool air.

Therefore, from nature's numerous examples, we can deduce that the humid rainforest zone require sprawling, well-aerated, narrow extroverted building plans with wide windows for through and cross ventilations. Similarly, the fishing camps in the Niger Delta replete with stilt habitats, built by the native fishing communities, as they evolve an effective folk architecture, gives us indigenous solutions to environmental conditions. On the other hand, the dry savannah with less relative humidity has trees with less leaves compared to the rainy south. Consequently, buildings in this zone require compact deep introverted plans, with narrow windows, shielded from the orientation of sandstorms and supported with humidifiers and adiabatic cooling systems. Thus, the northern farmer adopts the curvilinear scanty straw hut, with less extensive eaves, towards warding off the wild winds and sight-stealing sandstorms. Unfortunately, modern architects in Nigeria have not translated this effective primordial wisdom of the natives into a vernacular or any other kind of evolutionary architecture, as architects have done with the evolution of architecture in the advanced countries. Rather we have a bizarre indiscriminate eclectic combination of forms that do not follow function and environmental conditions. We can see clearly that designers and builder have ignorantly ignored the natural examples; thus, we find indiscriminate architecture strewn in the Nigerian climatic zones, which confront rather than conform to natural examples.

\section{Implication of Winds on Building Orientation in Nigeria}

Nigeria has two prevailing winds that play decisive roles in the design of buildings. These are the dust laden northeast wind from the Sahara desert and the moisture laden southwest wind from the Atlantic Ocean. According to the Beaufort Scale, the strength of the velocities of winds is divisible into thirteen scales, from calm at zero, to hurricane at twelve ${ }^{(9)}$, on the basis of which we can ascertain the proportional effects of winds on buildings and their constructions (Tables 1a and 1b). This enables us to classify and determine appropriate precautions in designing buildings fit for climatologically defined zones. Studies show that destructive winds ranging from 25 kilometres per hour and exceeding 118 kilometres per hour in the open field occur according to the prevailing winds in an inverse proportion to the density of the vegetation. The prevailing winds in the northern part of Nigeria accompanied by sandstorms and desertification occur from November to March and from April to October in the southern parts of Nigeria accompanied by thunderstorms. These observations call for pre-emptive precautions in building orientations, particularly those that are perpendicular to the Southwest and Northeast axis of the powerful prevailing winds. We know that buildings oriented at right angles to a strong prevailing wind suffer greater damage, compared to those at acute angles to the axis of the prevailing winds. ${ }^{(10)}$ Thunderstorms and sandstorms call for careful construction and landscaping, as defensive devices, against the natural forces of wind, desertification, denudation and degradation due to diverse disturbances to the environmental balance (Table 1). 
Tables: 1a-d. Characteristics Effects of Wind Type and Velocity on Human Environment 1 (a)

\begin{tabular}{|c|c|c|}
\hline Type of wind & Velocity of wind & Remarks \\
\hline calm & $0 \mathrm{kph}$ & $\begin{array}{l}\text { Uncomfortable Epicentres in Nigeria } \\
\text { All zones, with seasonal and spatial variation }\end{array}$ \\
\hline Light air & $3 \mathrm{kph}$ & $\begin{array}{l}\text { Comfortable Epicentres in Nigeria } \\
\text { All zones, with seasonal and spatial variation }\end{array}$ \\
\hline Light breeze & $9 \mathrm{kph}$ & $\begin{array}{l}\text { Comfortable Epicentres in Nigeria } \\
\text { All zones, with seasonal and spatial variation }\end{array}$ \\
\hline Gentle breeze & $15 \mathrm{kph}$ & $\begin{array}{l}\text { Comfortable Epicentres in Nigeria } \\
\text { All zones, with seasonal and spatial variation }\end{array}$ \\
\hline \multicolumn{3}{|r|}{1 (b) } \\
\hline Type of wind & Velocity of wind & Remarks \\
\hline Moderate wind & $25 \mathrm{kph}$ & $\begin{array}{l}\text { Uncomfortable Epicentres in Nigeria } \\
\text { All zones, with seasonal and spatial variation }\end{array}$ \\
\hline Fresh wind & $35 \mathrm{kph}$ & $\begin{array}{l}\text { Uncomfortable_Epicentres in Nigeria } \\
\text { All zones, with seasonal and spatial variation }\end{array}$ \\
\hline Strong wind & $45 \mathrm{kph}$ & $\begin{array}{l}\text { Uncomfortable Epicentres in Nigeria } \\
\text { All zones, with seasonal and spatial variation }\end{array}$ \\
\hline
\end{tabular}

1 (c)

\begin{tabular}{|c|c|c|}
\hline Type of wind & Velocity of wind & Remarks \\
\hline Near gale & $56 \mathrm{kph}$ & Destructive \\
\hline & & Epicentres in Nigeria \\
\hline & & All zones, with seasonal and spatial variation \\
\hline Gale & $68 \mathrm{kph}$ & $\begin{array}{l}\text { Destructive with damage to buildings Epicentres in Nigeria } \\
\text { All zones, with seasonal and spatial variation }\end{array}$ \\
\hline Severe gale & $81 \mathrm{kph}$ & Dangerous Epicentres in Nigeria \\
\hline
\end{tabular}

$1(d)$

\begin{tabular}{lll}
\hline Type of wind & Velocity of wind & Remarks \\
\hline Storm & $94 \mathrm{kph}$ & $\begin{array}{l}\text { Disastrous with widespread damage to buildings Epicentres in Nigeria } \\
\text { All zones, with seasonal and spatial variation }\end{array}$ \\
Severe storm & $110 \mathrm{kph}$ & $\begin{array}{l}\text { Disastrous widespread wreckage to buildings Epicentres in Nigeria } \\
\text { Kaduna, Mina, Makurdi, Yola, Bida, Ibadan, Oshogbo, Warri, Calabar, Port } \\
\end{array}$ \\
& & Harcourt, Benin City... \\
\hline Hurricane & $118 \mathrm{kph}$ & $\begin{array}{l}\text { Disastrous widespread wreckage to buildings Epicentres in Nigeria } \\
\text { Gusau, Maiduguri, Kano, Bauchi, Jos, Potiskum, Bida, Ikeja... }\end{array}$ \\
\hline
\end{tabular}

Temperature, Wind and Relative Humidity as a Measure of Comfort in Buildings

Temperature, Wind and Relative Humidity intertwine to determine the relative comfort that people feel. Accordingly, we have shared the territory of Nigeria into several isohyets and isobars to focus on the inseparable relationships between these parameters for building climatology. We have, therefore, presented the average temperatures, wind velocities and relative humidity for specific zones and locations in the southern rain forest and the northern savannah as follows (Tables: 1a-3c). We also acknowledge that the irregular climatic situation of Jos on the plateau; Enugu, Ikom and Obubra on hills, create peculiar cool climatic conditions, which make them desirable destinations for foreigners from temperate regions. These micro-climatic areas, coupled with the potential risks of erosions, denudation and the dynamics of atmospheric pressure, require a peculiar architectural expression in dealing with these uncharacteristic lower temperature regimes, in the otherwise tropical climate of Nigerian (Table 2).

Tables: 2 (a, \& b). Characteristic Climatic Conditions in Zones, Regions and Sub-Regions of Nigeria:

\begin{tabular}{llll} 
& \multicolumn{2}{c}{2 (a): Humid Zone I } \\
\hline Zone & Region & Sub-Region & Characteristic Climatic Conditions \\
\hline II & $\mathbf{2}$ & $2 \mathrm{~A}$ & Temperature $=27{ }^{\circ} \mathrm{C}$ \\
Humid & Humid Climate & & Relative humidity $80 \%$ \\
& & Hot humid weather \\
& & Temperature $=24-27 \circ^{\circ} \mathrm{C}$ \\
& & Relative humidity $80 \%$ \\
& & Hot humid weather at $25^{\circ} \mathrm{C}$ \\
& & Warm humid weather at $24-25^{\circ} \mathrm{C}$ \\
\hline & & Temperature $=24{ }^{\circ} \mathrm{C}$ \\
& & Relative humidity $80 \%$ \\
& & Warm humid weather \\
\hline
\end{tabular}

* Corresponding author: Imaah, N. O. 
2 (b) Humid Zone II

\begin{tabular}{|c|c|c|c|}
\hline Zone & Region & Sub-Region & Characteristic Climatic Conditions \\
\hline I & 1 & $1 \mathrm{~A}$ & Temperature (average) $\geq 27^{\circ} \mathrm{C}$ \\
\hline \multirow[t]{10}{*}{ Humid } & Relatively & & Warn if average temperature $=28 \circ \mathrm{C} ; \mathrm{R} . \mathrm{H} .=78 \%$ \\
\hline & Humid & & Hot if average temperature $=28 \circ$ C; R.H. $>75 \%$ \\
\hline & Climate & 1B & Temperature $\geq 24 \leq 27^{\circ} \mathrm{C}$ \\
\hline & & & Relative humidity $=60 \%-80 \%$ \\
\hline & & & Warn if average temperature $=24-28 \circ$ C; R.H. $=60-75 \%$ \\
\hline & & & Warn if temperature average $=24-25^{\circ} \mathrm{C} ; \mathrm{R} \cdot \mathrm{H} .=75-80 \%$ \\
\hline & & & Hot if average temperature $=25-27 \circ$ C; R.H. $>75-80 \%$ \\
\hline & & $1 \mathrm{C}$ & Temperature $=24 \circ \mathrm{C}$ \\
\hline & & & Relative humidity $60 \%-80 \%$ \\
\hline & & & Warm weather \\
\hline
\end{tabular}

Tables 3: (a-c). Building Climatology in Nigeria. 3(a): Dry Climatic Zone 1

\begin{tabular}{|c|c|c|c|}
\hline Zone & Region & Sub-Region & Characteristic Climatic Conditions \\
\hline & & \multirow[t]{2}{*}{$1 \mathrm{~A}$} & Temperature $\geq 27{ }^{\circ} \mathrm{C}$ \\
\hline Dry & Arid & & Relative humidity $\leq 20 \%$ \\
\hline & & & Warm and very dry weather \\
\hline & & 1B & Temperature $\geq 24 \leq 27{ }^{\circ} \mathrm{C}$ \\
\hline & & & Relative humidity $\geq 20 \% \leq 40 \%$ \\
\hline & & & Warm and dry weather \\
\hline & \multirow{9}{*}{$\begin{array}{l}2 \\
\text { Dry }\end{array}$} & $2 \mathrm{~A}$ & Temperature $27^{\circ} \mathrm{C}$ \\
\hline & & & Relative humidity $\geq 20 \% \leq 40 \%$ \\
\hline & & & Warm and dry, comfortable weather \\
\hline & & \multirow[t]{3}{*}{$2 \mathrm{~B}$} & Temperature $\geq 24 \leq 27{ }^{\circ} \mathrm{C}$ \\
\hline & & & Relative humidity $\geq 20 \% \leq 40 \%$ \\
\hline & & & Warm and dry comfortable weather \\
\hline & & \multirow[t]{3}{*}{$2 \mathrm{C}$} & Temperature $=24{ }^{\circ} \mathrm{C}$ \\
\hline & & & Relative humidity $\geq 20 \% \leq 40 \%$ \\
\hline & & & Warm and dry comfortable weather \\
\hline \multicolumn{4}{|c|}{3 (b): Normal Climatic Zone } \\
\hline Zone & Region & Sub-Region & Characteristic climatic conditions \\
\hline \multirow{9}{*}{$\begin{array}{l}\text { II } \\
\text { Normal }\end{array}$} & \multirow{9}{*}{$\begin{array}{l}1 \\
\text { Normal }\end{array}$} & \multirow[t]{3}{*}{$1 \mathrm{~A}$} & Temperature $\geq 27^{\circ} \mathrm{C}$ \\
\hline & & & Relative humidity $\geq 20 \% \leq 40 \%$ \\
\hline & & & Warm and dry comfortable weather \\
\hline & & \multirow[t]{3}{*}{ 1B } & Temperature $\geq 24{ }^{\circ} \mathrm{C} \leq 27{ }^{\circ} \mathrm{C}$ \\
\hline & & & Relative humidity $\geq 40 \% \leq 60 \%$ \\
\hline & & & Comfortable weather \\
\hline & & \multirow[t]{3}{*}{$1 \mathrm{C}$} & Temperature $=24^{\circ} \mathrm{C}$ \\
\hline & & & Relative humidity $\geq 40 \% \leq 60 \%$ \\
\hline & & & Comfortable weather \\
\hline
\end{tabular}

3 (c): Hot Humid Climatic Zone

\begin{tabular}{|c|c|c|c|}
\hline Zone & Region & Sub Region & Characteristic climatic conditions \\
\hline \multirow{15}{*}{$\begin{array}{l}\text { III } \\
\text { Humid }\end{array}$} & 1 & $1 \mathrm{~A}$ & Temperature $\geq 27^{\circ} \mathrm{C}$ \\
\hline & Mildly & & Relative humidity $\geq 60 \% \leq 80 \%$ \\
\hline & Humid & & hot and relatively humid weather \\
\hline & & 1B & Temperature $\geq 24{ }^{\circ} \mathrm{C} \geq 27{ }^{\circ} \mathrm{C}$ \\
\hline & & & Relative humidity $\geq 60 \% \leq 80 \%$ \\
\hline & & & Predominantly Warm weather \\
\hline & & $1 \mathrm{C}$ & Temperature $=24 \circ \mathrm{C}$ \\
\hline & & & Relative humidity $\geq 60 \% \leq 80 \%$ \\
\hline & 2 & $2 \mathrm{~A}$ & Temperature $\geq 24{ }^{\circ} \mathrm{C} \geq 27{ }^{\circ} \mathrm{C}$ \\
\hline & Humid & & Relative humidity $\geq 80 \%$ \\
\hline & & & Hot weather \\
\hline & & $2 \mathrm{~B}$ & Temperature $\geq 24{ }^{\circ} \mathrm{C} \geq 27{ }^{\circ} \mathrm{C}$ \\
\hline & & & Relative humidity $\geq 80 \%$ \\
\hline & & & Warm weather at $24^{\circ} \mathrm{C}-25^{\circ} \mathrm{C}$ \\
\hline & & & Predominantly hot weather at $25^{\circ} \mathrm{C}$ \\
\hline
\end{tabular}

From the analysis, we find that the "ComfortZone" depends on the combination of the direction of prevailing winds as well as their dynamic strength, the amount of rainfall, latitude and altitude, etc. ${ }^{(11)}$ We can deduce from the tables 2 and 3 above that the most comfortable zones have a temperature range of $24 \circ \mathrm{C}-27 \circ \mathrm{C}$ when the relative humidity range is $20 \%-60 \%$. Therefore, any climatic conditions outside this range require special air conditioning considerations. (Table 3) 


\section{The Environment and Climatic Zone in Nigeria}

The paper relates the peoples of Nigeria to the various environments and circumstances under discussion because the environment is inseparable from the people who live in it. Thus, the paper probes into the factors which have influenced the building industry in Nigeria. For instance, some of the earliest literary and artistic traditions in West Africa are still influential within the boundaries of modern Nigeria in spite of the fact that a valuable part of the Nigerian artistic and cultural heritage collections are sadly still captives in Diasporas. Hence, the paper posits that literary and artistic factors can induce an environmentally friendly architecture. Evidence shows that Nigeria has a long and rich tradition of producing works of art and literature. For example, Nok artists of northern Nigeria made terracotta sculptures as early as $500 \mathrm{BC}$ and Ife terracotta and Benin bronze works, first made about $1200 \mathrm{AD}$, are world famous. The Benin bronzes first brought the country's rich and ancient artistic and handcraft traditions to the notice of a wider world. Furthermore, traditional folk art and written vernacular literature, augmented professional theatre companies and dance groups, which subsequently, supplemented western-influenced graphics, painting, sculpture and architecture. Modern Nigerian literature is particularly rich in traditional oral literature, which according to Stock ${ }^{(12)}$, has had a significant impact on such worldfamous contemporary Nigerian writers such as the Nobel laureate, Wole Soyinka, Chinua Achebe, Amos Tutuola, and more recently Ben Okri. Superimposed on these educational traditions have been the influences of colonial rule and missionary systems of education. For instance, the British colonial period has continued to influence Nigerian literature and architecture very much.

However, these rich artistic and literary traditions have neither found their ways pervasively nor persuasively into forceful forms for the conceptualization and expression of an authentic Nigerian architectural landscape. For instance, the rich tradition of colonial architecture: deep eaves; appropriate pitched roof; "healthy breathing" earth or thick brick walls, is in keeping with the environment. Building science has proved that the thick wall is conscious of thermal and other environmental considerations, using local builders and building materials, such as treated clay and timber. However, architects, designers and government policies have frivolously forced the traditions of colonial architecture to yield its place to an indiscriminate "independent international architecture"; just for the kicks of emphasizing that Nigeria has attained independence from British colonial rule along with colonial architecture; thereby throwing away both the baby and the bathwater. Evidently, Nigerian architects and policymakers have not yet given constant conscious consideration to designing pleasing and appropriate buildings that incorporate and coalesce with the rich environmental and cultural heritage of Nigeria.

\section{The Human Environment: A Catalyst for Religious and Ethnic Riots}

The paper opines that good architecture should harmonize the environment with the way of life of the peoples it serves. However, the paper observes that the inharmonious multiplicity of ethnic groups, religions environments and eclectic architecture have generated a clash of cultures, religions, architectures and the various environments in recent years. Religion generates continual conflicts in Nigeria. A survey shows that at least 50 per cent of Nigerian peoples are Muslim, the bulk of who live in the Hausa, Fulani, and Kanuri areas in the north. About 40 per cent of Nigerian peoples are Christians; Roman Catholicism has its concentration in the southeast, while Methodism and other Christian denominations and sects have a strong following in various parts of both the southeast and southwest. Some 18 per cent Nigerians practice traditional religions. Religion therefore has greatly influenced architecture within Nigeria. The Arabic Islamic architecture and the western Christian architecture predominate in their respective high-density domains in Nigeria. Usually people make religious architecture more sentimentally attached to their origins and symbols rather than their attachments to environmental conditions and destinations. Therefore, religious architecture often voluntarily violates environmental imperatives. In recent years, ethnic and religious tensions and rivalry have resulted in the outbreaks of communal violence. We have come to the considered opinion that whenever or whenever the new architecture and culture do not fit sensitively, and in harmony with the environmental temperature and temperament, intolerance, invariably, sets in. Furthermore, whenever mundane culture clashes with rigid religious relationships, the result is riots. The recent Kaduna, Zango-kataf, Jos and Lagos religious riots are instructive. Therefore, we recommend that architects, appropriate governmental and nongovernmental agencies must make effective efforts to collocate Christian churches, Muslim mosques, sacred shrines and grooves, with circumspect, in the human and natural environment to avoid catastrophic clash of cultures in sacred and secular architecture in opposition to the socio- cultural environments.

\section{CONCLUSIONS}

The heterogeneous nature of Nigerian vegetation, climatic conditions, socio-cultural conditions and religions in flux, calls for a complex systems approach to building in accordance with the 
specificities of the environment; and not the contemporary chaos, because whenever the sociocultural landscape deteriorates; there is correlated wanton destruction to the built human and natural environment. The studies and analysis confirm that ample examples involving the aesthetic synthesis of nature into architecture are not only visibly viable but also desperately desirable. The paper has, therefore, examined and found plausible constructional and formal expressions in the Nigerian natural environment, which builders could recommend for ameliorating the waning manmade environment. Specifically, the paper has identified two major climatic zones in Nigeria: the southern rain forest terrain and the northern scorched savannah, which were further, fragmented into more detailed definable building climatologically zones. We proposed two types of building plans for Nigeria: the open plan for the humid zones, and the compact plans for the dry savannas respectively; using examples from dendrological analysis to derive suitable types of roofs, fenestrations, and wall thicknesses.

Also examined was the human environment, specifically, in order to trace the causes of religious riots, clash of cultures and antagonistic architecture, in relationship to the natural environment in a move towards creating an enabling environment for peaceful coexistence. The paper identifies and proposes a number of rational ways of simulating natural phenomena into creating stimulating and environmentally conscious building construction and architectural design. Based on these factors, the paper proposes a climatic and environmental model space for architectural design, which could also be adaptable as a methodology, in Nigeria and other global climatic regions.

\section{REFERENCES}

Stock, R (2003). Microsoft Encarta Encyclopaedia

Stock, R (2003). Microsoft Encarta Encyclopaedia

Stock, R (2003). Microsoft Encarta Encyclopaedia

Emerson, R W (1995). "Nature, History,"

Claremont's (eds.), A Dictionary of

Quotations, London: Claremont Books, p. 86.

Ark, D. V. (1977). A teacher's guide to the Garden and the City, Chicago: Literature of the Bible, Inc, p.38.

Tisa, A. A (1976). Basics of Architectural Composition and Design, Izdatelskoe biedinienie Vhisha Shkola, Golovnoye Izdatelstvo, Kiev, pp. 194-199. (In Russian)

Tisa, A. A (1976). Basics of Architectural Composition and Design, Izdatelskoe Obiedinienie Vhisha Shkola, Golovnoye Izdatelstvo, Kiev, p. 192. (In Russian)R. Stock, 2003 Microsoft Encarta Encyclopaedia

Taylor, B (1997). Everyday Science about the Weather, Macdonald Young Books, East Sussex, p. 13.

Iloeje, N P (1981). A New Geography of Nigeria, Longmans Nigeria Limited, pp. 100-104.

Urmanov, R C (1982). "Climatic-Environmental Model of Space for Architectural Design," in Basics of Architectural Design, Tomsk: Gosuniversitet, 15 pages. (In Russian)

Stock, R (2003). Microsoft Encarta Encyclopaedia. 